\title{
Efficient Removal of Chromium(VI) Using a Novel Waste Biomass Chestnut Shell-Based Carbon Electrode by Electrosorption
}

\author{
Xiaofei Zhang, Bo Ren, Xiaonan Wu,* Xin Yan, Yu Sun, Hongcheng Gao, and Feng Qu
}

Cite This: ACS Omega 2021, 6, 25389-25396

Read Online

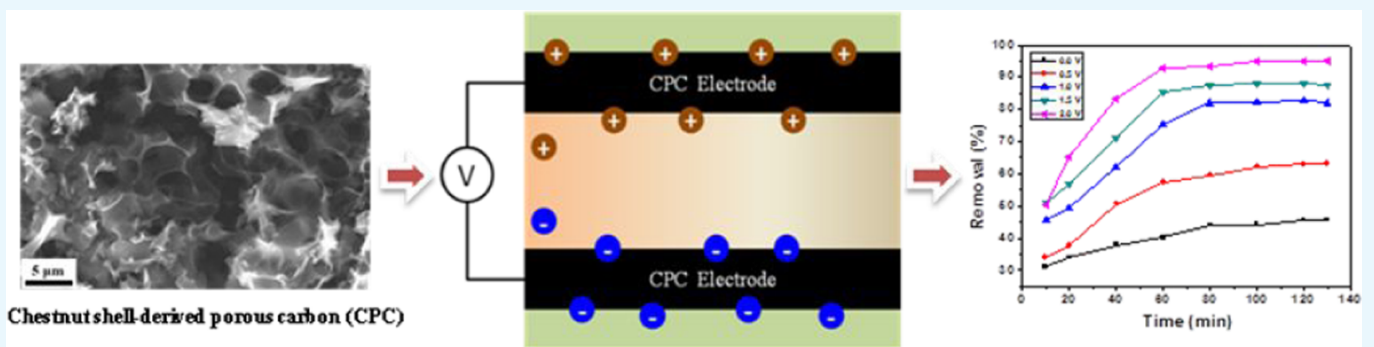

ABSTRACT: Biomass-derived porous carbon materials have a good application prospect in electrosorption because of their low cost, abundant natural resources, and excellent performance. In this work, three-dimensional interconnected structure porous carbon (CPC) was successfully synthesized from waste biomass chestnut shells by carbonization and chemical activation processes. The unique structure of CPC could offer superior double-layer capacitance and excellent conductivity. The as-obtained CPC was applied as an electrosorption electrode. In the deionization experiments, the removal efficiency of the CPC electrode in a $30 \mathrm{mg} \mathrm{L}^{-1}$ chromium(VI) aqueous solution at $1.0 \mathrm{~V}$ was $90.5 \%$. The electrosorption follows pseudo-second-order kinetics. The CPC electrode also presented good regeneration performance in the regeneration test. These results demonstrate that the as-prepared carbonaceous material is an ideal material for capacitive deionization electrodes.

\section{INTRODUCTION}

Chromium(VI) has been widely used in industries, such as corrosion protection, textile, pigment manufacturing, leather tanning, and electroplating. ${ }^{1,2}$ Chromium(VI) is a nonbiodegradable and toxic pollutant that can cause nausea, nervous disorder, kidney failure, and liver diseases. ${ }^{3-5}$ Therefore, developing effective methods to remove chromium(VI) from wastewater is very important. Over the years, various technologies have been studied for removing chromium(VI), including chemical precipitation, membrane filtration, ion exchange, reverse osmosis, electrosorption, and so on. ${ }^{6-10}$

Electrosorption is an emerging wastewater treatment technology due to its environmental friendliness, low energy consumption, low cost, and easy regeneration. ${ }^{11-14}$ The electrosorption is an electrochemically controlled method based on an electric double-layer capacitor (EDLC) to remove ions. ${ }^{15}$ Under the action of an external power supply, ions in the solution are adsorbed to the electrode, thus removing ions. Electrode regeneration is realized by a short circuit or applying reverse voltage. ${ }^{16,17}$ According to the electrosorption process, the structure and properties of electrode materials determine the capacitive deionization ability. ${ }^{13,18}$ The ideal capacitive deionization electrode should possess high specific surface area, good electric conductivity, high specific capacitance, and reasonable pore size distribution. In addition, chemical stability and cost issues are considerable as well. Carbon materials meet most of these criteria. Up to now, activated carbon, ${ }^{19}$ graphene, ${ }^{20,21}$ carbon aerogels, ${ }^{22}$ carbon nanofibers, ${ }^{23,24}$ and carbon nanotubes ${ }^{25,26}$ have been studied by researchers. However, the development has been limited by these carbon materials with complex synthesis processes and high costs, particularly in wastewater treatment. ${ }^{27}$ The development of high adsorption efficiency and low-cost capacitive deionization electrode materials in water treatment has always been the research target.

A biomass-derived carbon material is the most potential industrialized electrode material, which has abundant existence on earth, simple preparation method, nontoxic and pollutionfree, rich pore structure, good electrical conductivity, strong chemical stability, and low price. Therefore, the biomassderived carbon material as a capacitive deionization electrode material is very suitable. ${ }^{28,29}$ For instance, Liu and Tang ${ }^{30}$ using sugarcane bagasse as a precursor material prepared biomass-derived carbon electrodes via microwave carbon-

Received: June 25, 2021

Accepted: September 8, 2021

Published: September 21, 2021 

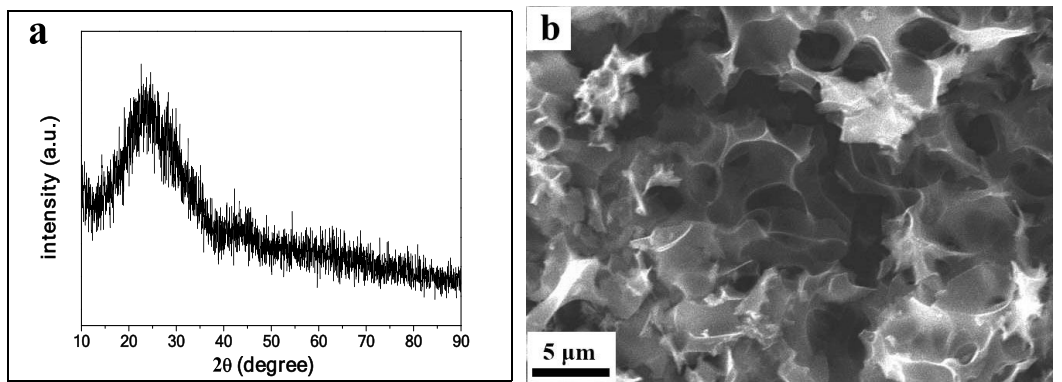

Figure 1. XRD pattern of CPC (a) and scanning electron microscopy (SEM) image of CPC (b).

ization and activation. Zhao et al. ${ }^{31}$ prepared the carbon material from watermelon peel and the obtained carbon material was developed as electrodes for deionization capacitors.

Chestnuts are widely cultivated as food and medicine throughout the world. As the residual product of chestnuts, millions of tons of chestnut shells have been directly abandoned every year, resulting in a massive waste of resources. Therefore, it is significant to synthesize carbon materials from chestnut shells for high-performance capacitive deionization applications. Herein, we provide a green and economical route to synthesize the carbon material from the chestnut shells through carbonization and chemical activation. The obtained carbon material has a three-dimensional interconnected porous structure. The unique structure of porous carbon (CPC) could offer superior double-layer capacitance and excellent conductivity. As expected, CPC showed a high removal efficiency of $90.5 \%$ in a $30 \mathrm{mg} \mathrm{L}^{-1}$ chromium(VI) aqueous solution at $1.0 \mathrm{~V}$. These findings suggest that the CPC electrode should be an ideal electrode material for electrosorption. This study realizes the resource utilization of waste chestnut shells and provides an effective measure for removing chromium(VI), which has high application value.

\section{RESULTS AND DISCUSSION}

Structural Characterization. The X-ray diffraction spectrum of CPC is shown in Figure 1a. The X-ray powder diffractometer (XRD) pattern of CPC exhibits two wide diffraction peaks corresponding to (002) and (100) planes, indicting the partial graphitization of the samples. ${ }^{32,33}$

The morphology of CPC was observed by SEM. As can be seen from Figure $1 \mathrm{~b}, \mathrm{CPC}$ has many macropores, which are interconnected to form a connected three-dimensional channel. The connected three-dimensional channel forms an ion buffer layer, which shortens the ion diffusion distance. ${ }^{34-36}$ In contrast, hydrothermal carbon $(\mathrm{CHC})$ and $700{ }^{\circ} \mathrm{C}$ calcined hydrothermal carbon (DCHC) show bulk structures without pores (Figure $\mathrm{S} 1$ in the Supporting Information). This indicates that $\mathrm{KOH}$ plays a critical role in the formation of the three-dimensional interconnected porous structure. During the calcination process, $\mathrm{KOH}$ reacts with $\mathrm{C}$ as follows. ${ }^{37,38}$

$$
2 \mathrm{C}+6 \mathrm{KOH} \rightarrow 2 \mathrm{~K}+3 \mathrm{H}_{2}+2 \mathrm{~K}_{2} \mathrm{CO}_{3}
$$

The resulting metal $\mathrm{K}$ can effectively insert/penetrate the carbon matrix, thus increasing the lattice spacing of carbon. When treated with $1 \mathrm{M} \mathrm{HCl}$, metal $\mathrm{K}$ and other $\mathrm{K}$ salts were quickly removed, and the extended carbon lattice could not be restored to the original compact structure. Therefore, the three-dimensional interconnected porous structure was cre- ated. $^{39}$ The composition of chestnut shells from different sources may be slightly different. Therefore, we choose different sources of chestnut shells for comparison. The result shows that the morphology of obtained CPC presents no significant change, as shown in Figure S2.

The carbonization temperature also has a great effect on the morphology and electric adsorption performances. Figure S3 shows the SEM images of CPC-400 and CPC-550. It can be observed that when the calcination temperature is $400{ }^{\circ} \mathrm{C}$, the biomass carbon material structure is relatively dense, with a very small number of pores. With the increase of carbonization temperature, the number of pores in the product gradually increases. The reason is that activation is more complete at higher temperatures. ${ }^{31}$ When calcination temperature increases to $700{ }^{\circ} \mathrm{C}$, the product has three-dimensional interconnected channels and many pores. A highly interconnected porous structure facilitates the rapid transfer of electrons and the rapid diffusion of electrolyte ions, leading to greatly improved electrochemical performances.

The specific surface area and porous features of CPC were investigated by nitrogen adsorption-desorption isothermal analysis (Figure 2). The specific surface area of CPC is $429 \mathrm{~m}^{2}$ $\mathrm{g}^{-1}$ as calculated by the Brunauer-Emmett-Teller (BET) method. CPC shows a mesopore distribution at $3.84 \mathrm{~nm}$. As presented by the SEM image and nitrogen adsorptiondesorption isotherm, CPC possesses a hierarchical porous structure with macroporous and mesoporous features. For comparison, $\mathrm{CHC}$ was also investigated (Figure S4). The specific surface area and pore volume of CHC are $29 \mathrm{~m}^{2} \mathrm{~g}^{-1}$ and $0.08 \mathrm{~cm}^{3} \mathrm{~g}^{-1}$, respectively, which are significantly lower than those of CPC. Furthermore, it can be seen from SEM that $\mathrm{CPC}$ has a large number of macropores. In contrast, $\mathrm{CHC}$ shows a bulk structure without pores. The electrosorption performance depends largely on the pore structure of the electrode material. The hierarchical and interconnected pore structure can form a good ion transfer pathway to shorten the ion diffusion distance, thus accelerating ion transport. ${ }^{40}$ Such a feature is better for the enhanced capacitive deionization performance.

Electrochemical Performance. Cyclic voltammetry (CV) measurements of the $\mathrm{CHC}, \mathrm{DCHC}$, and $\mathrm{CPC}$ electrodes were first performed to investigate the electrochemical properties (Figure 3). CV measurements were performed in a $1 \mathrm{M}$ $\mathrm{Na}_{2} \mathrm{SO}_{4}$ electrolyte and a potential window ranging from 0 to $0.8 \mathrm{~V}$. Obviously, the CV curve integrated area of CPC sample is the largest among all carbon materials, indicating that the CPC sample has the highest electrochemical specific capacitance. Such a high specific capacitance also reflects the high capacitive deionization ability of CPC. In addition, the electrochemical performance of the samples obtained from 

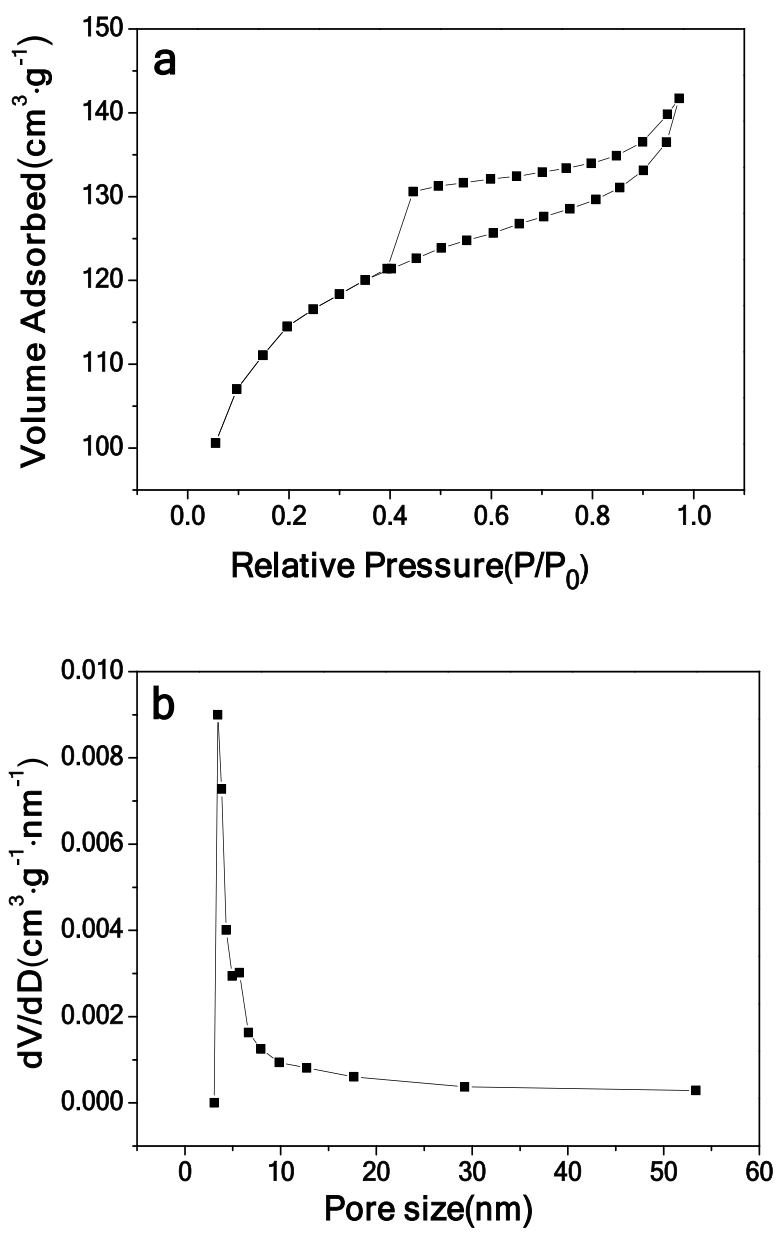

Figure 2. $\mathrm{N}_{2}$ sorption isotherm (a) and pore size distribution (b) of CPC.

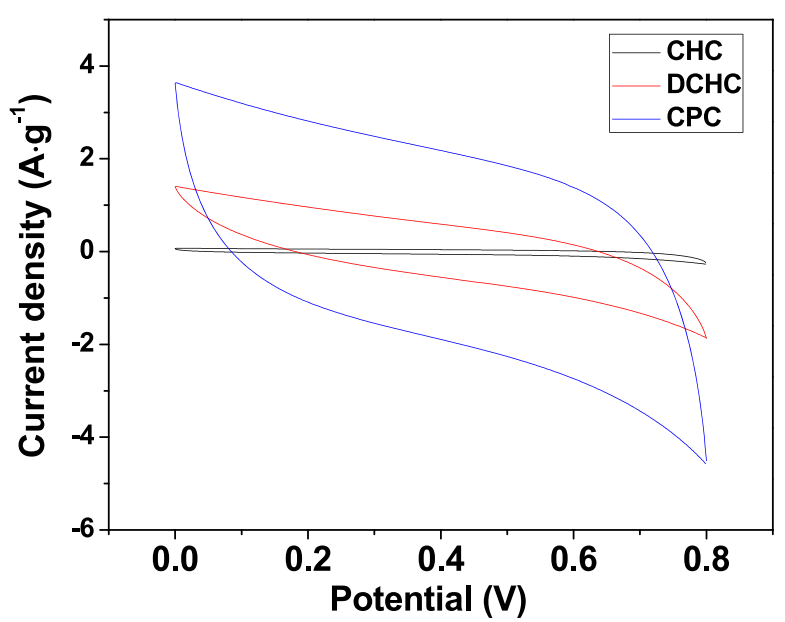

Figure 3. Comparison of electrochemical properties of $\mathrm{CHC}$, DCHC, and $\mathrm{CPC}$.

different carbonization temperatures (400 and $550{ }^{\circ} \mathrm{C}$ ) was also tested (shown in Figure 4). Significantly, compared with CPC-400 and CPC-550, the specific capacitance of CPC is much higher than those of CPC-400 and CPC-550. The CPC electrode offers the best performances that can be summarized in the following reasons. CPC has a stable three-dimensional honeycomb structure and abundant macropores and mesopores. The unique structure of CPC can not only offer a large

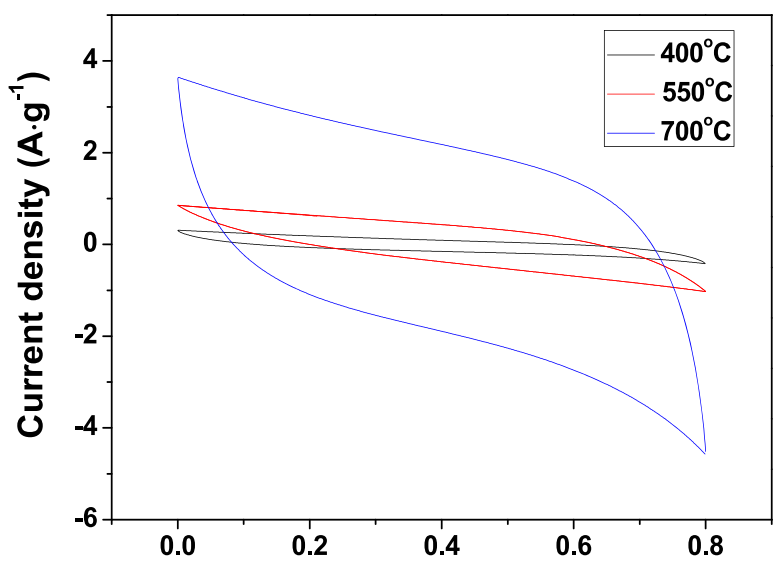

Figure 4. Comparison of electrochemical properties of CPC-400, CPC-550, and CPC.

contact area with the electrolyte but also promote electronic transport, which accelerates ion kinetic in the interior of the CPC electrode. ${ }^{41-44}$

The CV behavior of the CPC electrode at $10-100 \mathrm{mV} \mathrm{s}^{-1}$ scanning rates was tested (shown in Figure 5a). At high CV scan rates, the $\mathrm{CV}$ curves of $\mathrm{CPC}$ can still maintain a rectangular-like shape, indicating excellent rate capability. At a
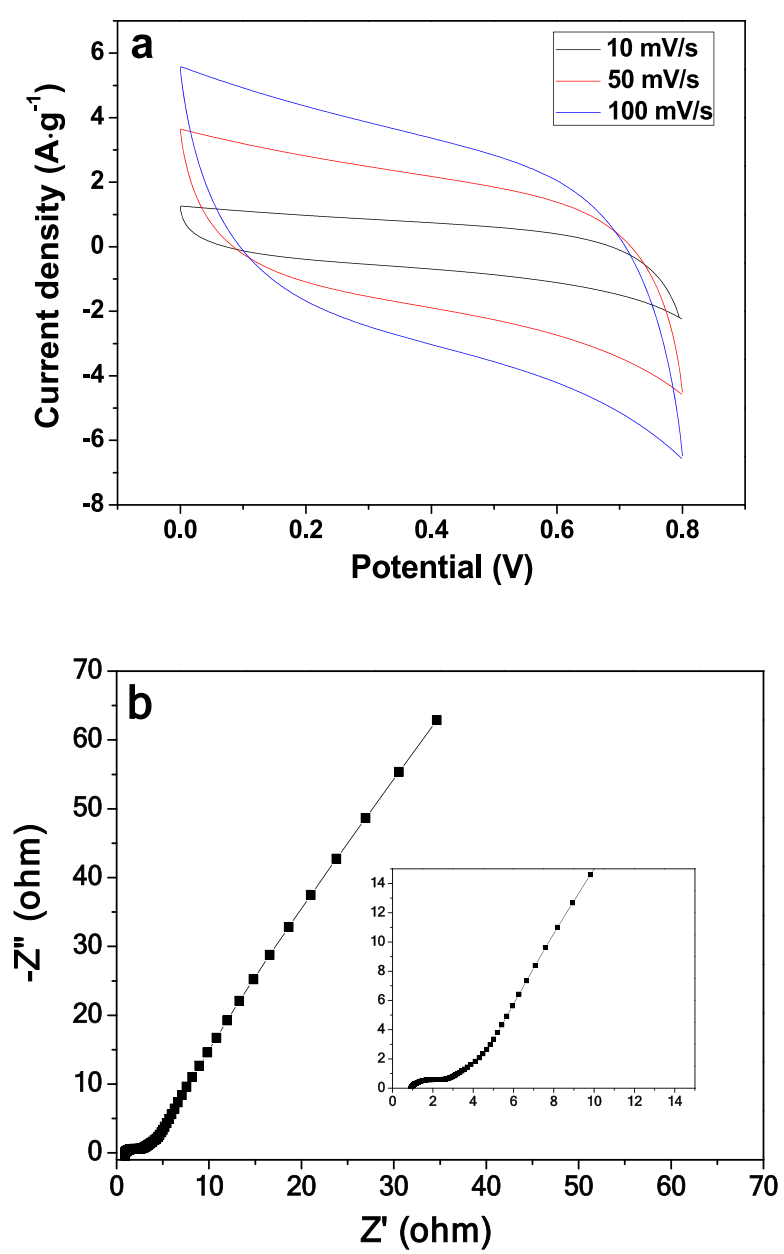

Figure 5. CV curves of the CPC electrode at various scan rates (a) and Nyquist profile of the CPC electrode (the inset is the enlarged view of the high-frequency region) (b). 
scanning rate of $10 \mathrm{mV} \mathrm{s}^{-1}$, the specific capacitance of the CPC sample is $131 \mathrm{~F} \mathrm{~g} \mathrm{~g}^{-1}$. The capacitance of the electrode directly affects the adsorption performance of the electrode. Therefore, compared with the specific electric capacity of relevant carbon materials, CPC prepared in this study has certain competitiveness.

Electrode conductivity and ion diffusion are very important for the capacitance and capacitive deionization performance of materials. Therefore, electrochemical impedance spectroscopy (EIS) was used to characterize the impedance performance of $\mathrm{CPC}$, as shown in Figure $5 \mathrm{~b}$. The frequency range of EIS is $0.01 \mathrm{~Hz}-100 \mathrm{kHz}$, and the AC amplitude is $5 \mathrm{mV}$. CPC shows a small semicircle diameter and a low intercept with $Z^{\prime}$ in the high-frequency region, indicating that $\mathrm{CPC}$ has small charge transfer resistance and high conductivity ${ }^{45,46}$ Based on the above electrochemical performance test results, it can be inferred that CPC has great application prospects in the field of electrosorption.

Electrosorption Performance. To study the electrosorption performance of $\mathrm{CPC}$, the electrosorption experiments of chromium(VI) on the CPC, CHC, and DCHC electrodes were carried out at $1.0 \mathrm{~V}$. The plot of removal efficiency versus deionization time is shown in Figure 6. Under identical

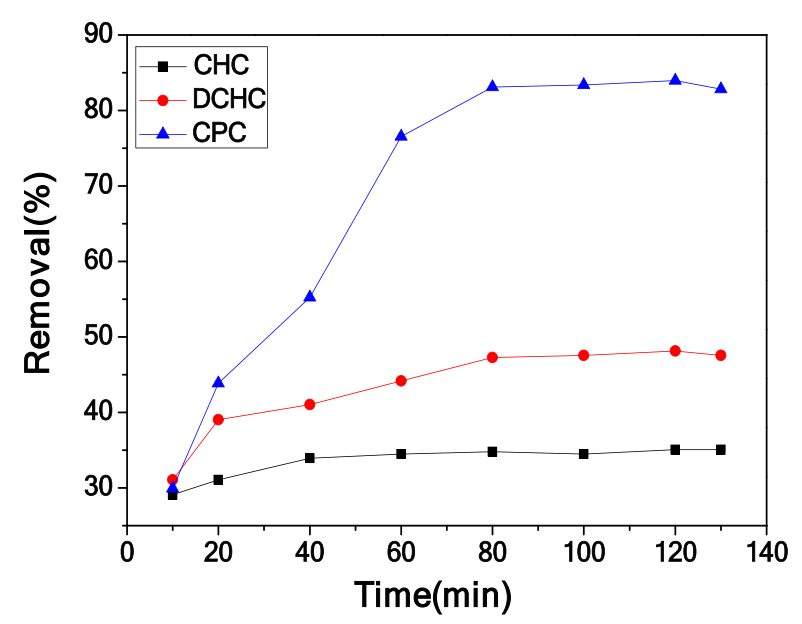

Figure 6. Electrosorption curves of $\mathrm{CHC}$, DCHC, and CPC.

conditions, the electrosorption capacity of chromium(VI) by $\mathrm{CHC}$ and DCHC is significantly lower than that of CPC. This is because CPC has a three-dimensional framework and a hierarchical porous structure composed of macropores and mesopores. In the process of electric adsorption, it can provide more ion accumulation and adsorption sites, which is beneficial to improve the removal efficiency. In addition, electrosorption performance tests were performed on the electrodes at different carbonization temperatures (400 and $550{ }^{\circ} \mathrm{C}$ ). Compared with CPC-400 and CPC-550, the removal efficiency of the CPC electrode is higher than those of CPC-400 and CPC-550 (shown in Figure 7). In general, the CPC electrode has the best performance, which may be due to its stable threedimensional honeycomb structure and abundant macropores and mesopores.

To investigate the effect of voltage on the electrosorption performance, the adsorption experiments of the CPC electrode under different voltages were carried out (shown in Figure 8). From 0 to $2.0 \mathrm{~V}$, the removal efficiency increases from 45.6 to $94.7 \%$, indicating that the higher the voltage, the higher the

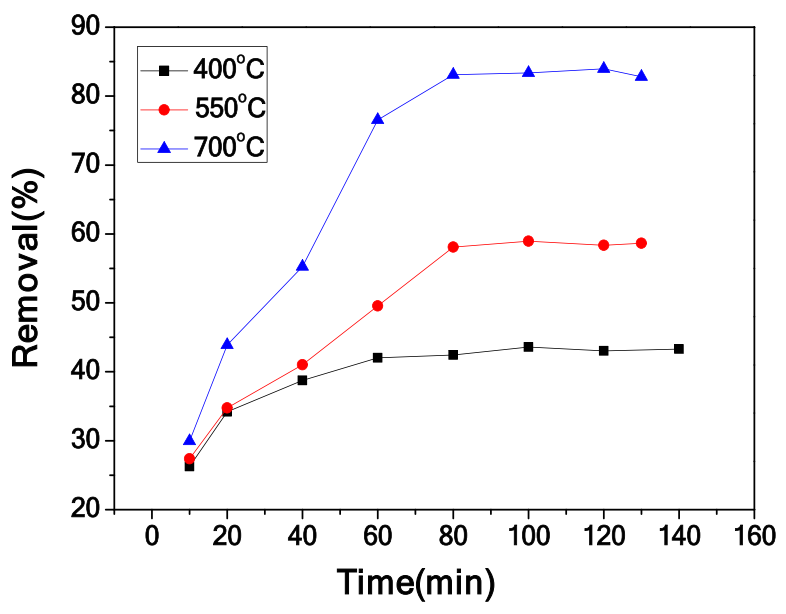

Figure 7. Electrosorption curves of CPC-400, CPC-550, and CPC.

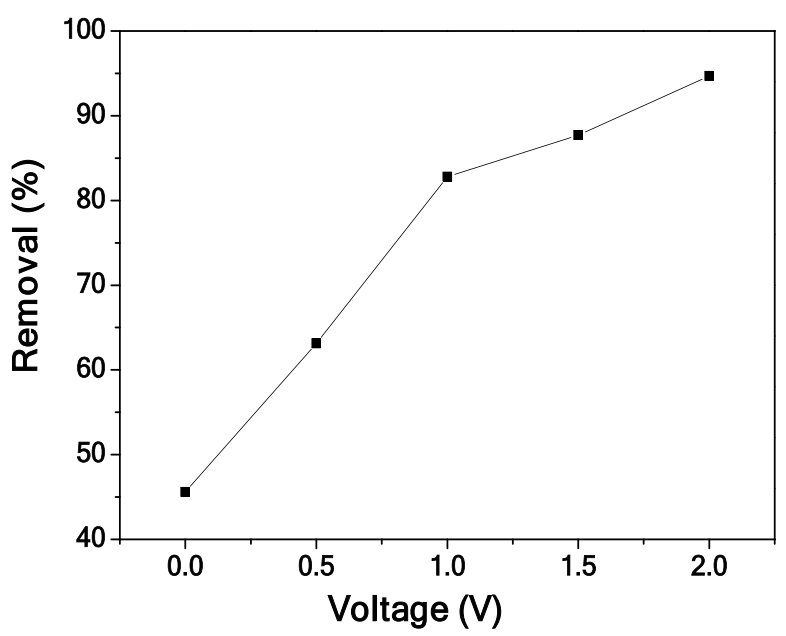

Figure 8. Effect of applied voltages on the electrosorption chromium(VI) performance of CPC.

electrosorption efficiency. This is mainly because as the voltage increases, the electrostatic force increases and the EDLC thickens. It is also worth noting that the theoretical decomposition voltage of water is $1.23 \mathrm{~V} .^{47}$ Excessive voltage will increase operation energy consumption.

In practical application, the background ions have a great influence on the electric adsorption performance. The effect of electrolyte concentration on the electrosorption performance of CPC was studied with $\mathrm{NaCl}$ as the representative background electrolyte. As can be seen from Figure 9, with the increase of $\mathrm{NaCl}$ solution concentration, the removal efficiency of chromium(VI) ions increases from 82.8 to $90.5 \%$. The improvement of removal efficiency can be explained as the conductivity increases with the addition of the electrolyte, and the migration rate of ions accelerates. ${ }^{48,49}$

To explore the influence of adsorption time on the electrosorption performance of CPC, the adsorption kinetics of CPC on chromium(VI) was studied by changing the adsorption time with other experimental conditions unchanged, as given in Figure 10. The result shows that the adsorption rate of CPC to chromium(VI) is very fast in the initial stage and gradually slows down until equilibrium. In the initial stage, a large number of chromium(VI) ions in the solution resulted in a high adsorption rate. As the adsorption process progresses, the number of chromium(VI) ions 


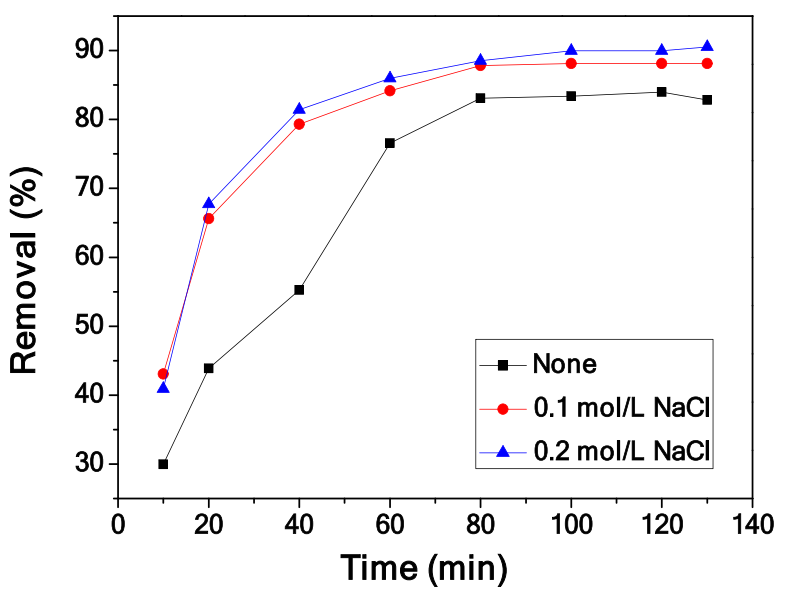

Figure 9. Effect of the electrolyte ion concentration on electrosorption.

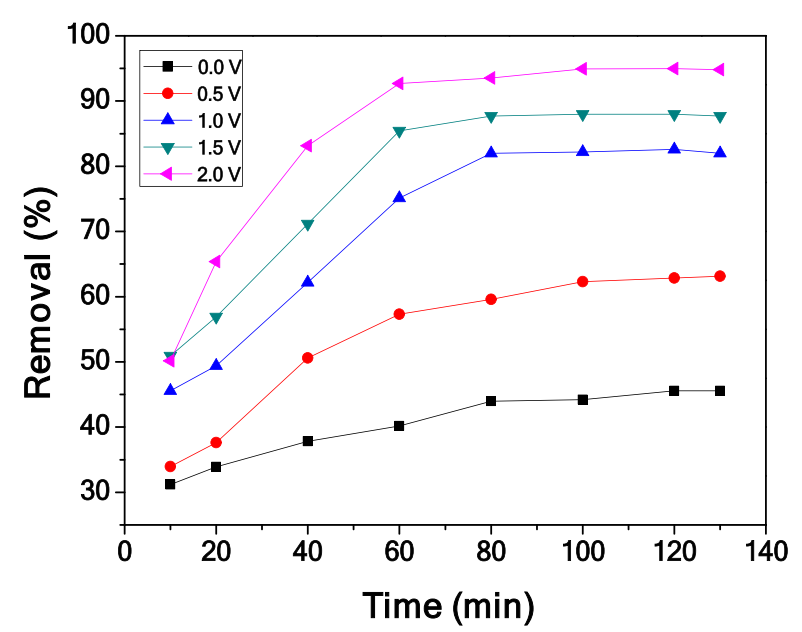

Figure 10. Effect of contact time on the electrosorption performance of CPC.

decreases, leading to the decrease of the adsorption rate. Moreover, as the active center is occupied, it is not conducive to further adsorption.

The adsorption kinetics of the capacitive deionization process was studied. ${ }^{50-53}$ The electrosorption kinetics of chromium(VI) on the CPC electrodes at different voltages is shown in Figure 11. The kinetic adsorption parameters of chromium(VI) are listed in Table 1. At each applied voltage, the pseudo-second-order fitting data are better than the pseudo-first-order fitting data, which indicates that the pseudosecond-order model can better describe the adsorption and electric adsorption processes. This deionization process is because of the electrostatic interaction between ions and the electrode. ${ }^{54,55}$

The recycling stability of the CPC electrode was also investigated. The cyclic test was carried out in the chromium(VI) solution at $1.0 \mathrm{~V}$. As shown in Figure 12, the electrosorption capacity is not significantly reduced after 10 cycles, indicating that $\mathrm{CPC}$ has excellent recycling ability. Therefore, CPC should be a promising electrode material for electrosorption.

Table S1 compares the removal efficiency of CPC with those of other adsorbents reported in the literature. ${ }^{55-57}$ The result shows that CPC has a good ability to remove chromium(VI). As the residual product of chestnuts, millions of tons of
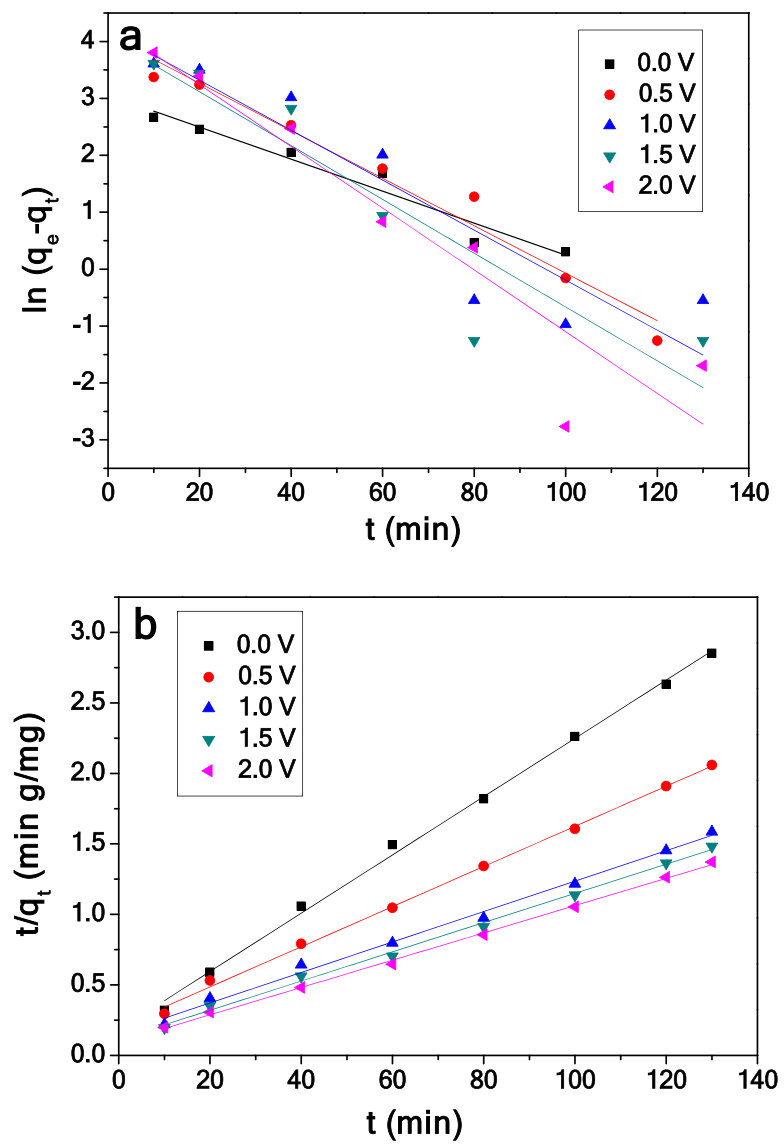

Figure 11. Fitting plots on chromium(VI) adsorption by the CPC electrode using pseudo-first-order (a) and pseudo-second-order (b) kinetic equations.

Table 1. Kinetic Parameters for Chromium(VI) Electrosorption by the CPC Electrode

\begin{tabular}{|c|c|c|c|c|c|}
\hline & 0 & 0.5 & 1.0 & 1.5 & 2.0 \\
\hline \multicolumn{6}{|c|}{ Applied Voltages (V) } \\
\hline $\begin{array}{c}q_{\mathrm{e}}(\exp )(\mathrm{mg} \\
\left.\mathrm{L}^{-1}\right)\end{array}$ & 43.18 & 59.81 & 77.68 & 83.09 & 89.71 \\
\hline \multicolumn{6}{|c|}{ Pseudo-first-order } \\
\hline$\underset{\left.\mathrm{L}^{-1}\right)}{q_{\mathrm{e}}(\mathrm{cal})}(\mathrm{mg}$ & 21.26 & 57.12 & 63.05 & 55.01 & 71.63 \\
\hline$k_{1}\left(\min ^{-1}\right)$ & 0.0281 & 0.0417 & 0.0439 & 0.0473 & 0.0542 \\
\hline$R^{2}$ & 0.934 & 0.965 & 0.829 & 0.820 & 0.867 \\
\hline \multicolumn{6}{|c|}{ Pseudo-second-order } \\
\hline$\underset{\left.\mathrm{L}^{-1}\right)}{q_{\mathrm{e}}(\mathrm{cal})}(\mathrm{mg}$ & 48.40 & 66.53 & 87.72 & 91.49 & 97.85 \\
\hline $\begin{array}{c}k_{2}[\mathrm{~g}(\mathrm{mg} \\
\left.\min )^{-1}\right]\end{array}$ & 0.0023 & 0.0011 & 0.0011 & 0.0010 & 0.0010 \\
\hline$R^{2}$ & 0.997 & 0.998 & 0.994 & 0.996 & 0.998 \\
\hline
\end{tabular}

chestnut shells have been directly abandoned or burnt every year, resulting in massive waste of resources. In addition, burning it can cause air, water, and soil pollution. Using waste chestnut shells as a carbon source can not only reduce the cost but also alleviate environmental pollution. In summary, this study realizes the resource utilization of waste chestnut shells and provides an effective measure for removing chromium(VI). 


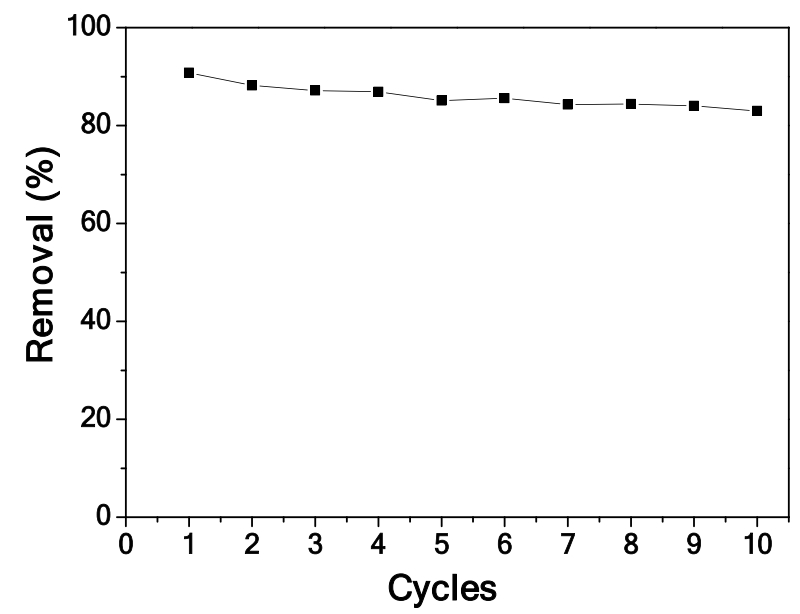

Figure 12. Cycling stability test of the CPC electrode.

\section{CONCLUSIONS}

In summary, we provide a green and economical route for synthesizing the carbon material from chestnut shells by carbonization and chemical activation processes. The obtained CPC material has a three-dimensional frame structure with interconnected channels and abundant macropores and mesoporous. Because of the unique structure, the CPC electrode has satisfactory electrosorption performance. The CPC-based capacitive deionization showed a high chromium(VI) removal efficiency of $90.5 \%$ at $1.0 \mathrm{~V}$. The adsorption kinetics were found to best agree with the pseudo-secondorder model. Besides, the CPC electrode showed good regeneration behavior. These results demonstrate that CPC with three-dimensional interconnected porous structures derived from chestnut shells should be an ideal electrode material for capacitive deionization.

\section{EXPERIMENTAL SECTION}

Preparation of Samples. The chestnut shell wastes were collected from farms and then crushed. The crushed chestnut shells were cleaned and dried in an oven at $100{ }^{\circ} \mathrm{C}$. Chestnut shells $(7.5 \mathrm{~g})$ were added to $70 \mathrm{~mL}$ of the citric acid solution $(0.1 \mathrm{M})$ under vigorous stirring. The obtained mixture was transferred to an autoclave and reacted at $200{ }^{\circ} \mathrm{C}$ for $6 \mathrm{~h}$. The resultant hydrothermal carbon (CHC) was recovered by filtration.

A certain amount of $\mathrm{CHC}$ was immersed in the $\mathrm{KOH}$ solution $(4 \mathrm{M})$ for $12 \mathrm{~h}$, filtered, and freeze-dried for $48 \mathrm{~h}$. Subsequently, the mixture was heated to $350{ }^{\circ} \mathrm{C}$ for $1 \mathrm{~h}$ in an $\mathrm{Ar}$ atmosphere. Then, the temperature was increased to 700 ${ }^{\circ} \mathrm{C}$ for $2 \mathrm{~h}$. The resulting black powder was soaked in $\mathrm{HCl}$ (1 M) for $6 \mathrm{~h}$ and then washed with deionized water to neutral. The chestnut shell-based biomass carbon material was obtained.

To study the influence of pyrolysis treatment temperature on the products, the final pyrolysis treatment was carried out at 400 and $550{ }^{\circ} \mathrm{C}$. The products were named $\mathrm{CPC}-400$ and $\mathrm{CPC}-550$, respectively. Without $\mathrm{KOH}$ activation treatment, hydrothermal carbon was directly heated to $350{ }^{\circ} \mathrm{C}$ in an $\mathrm{Ar}$ atmosphere and heat-treated for $1 \mathrm{~h}$. Then, the temperature was increased to $700{ }^{\circ} \mathrm{C}$ for $2 \mathrm{~h}$. The resulting sample was named DCHC.

Characterization. The crystal structure, surface morphology, and specific surface area of the samples were characterized using an X-ray powder diffractometer (Rigaku D/max-IIIB diffractometer XRD), a scanning electron microscope (Philips XL30 SEM), and a surface area and porosity analyzer (Quantachrome 2010e), respectively.

The electrochemical performance of the biochar electrode was evaluated by cyclic voltammetry (CV) and electrochemical impedance spectroscopy (EIS) on an electrochemical workstation (CHI660E). A standard three-electrode test system including a platinum counter electrode, a saturated calomel electrode, and a CPC working electrode was used in the test process. The working electrode consisted of CPC (80 wt \%), PTFE (10 wt \%), and acetylene black (10 wt \%). After ultrasonication, the mixture was coated on nickel foam $(1 \times 1$ $\mathrm{cm}^{2}$ ) and dried at $60{ }^{\circ} \mathrm{C}$. The specific capacitances were calculated by eq 1

$$
C=\int i \mathrm{~d} V / \nu \Delta V m
$$

where $i, v, \Delta V$, and $m$ denote the real-time current density, the potential scan rate, the potential window, and the weight of active CPC loaded on nickel foam, respectively.

Electrosorption Experiments. Electrosorption experiments were carried out in a cuvette with the chromium(VI) aqueous solution $\left(30 \mathrm{mg} \mathrm{L}^{-1}\right)$. The electrodes consisted of CPC ( $80 \mathrm{wt} \%)$, PTFE (10 wt \%), and acetylene black (10 wt $\%)$. The carbon slurry was coated on nickel foam and then transferred to a $60{ }^{\circ} \mathrm{C}$ oven for one night. The size of electrodes was set to be $2 \times 2 \mathrm{~cm}^{2}$. In the electroadsorption experiment, the capacitive deionization reactor was precharged with the specified voltage for $10 \mathrm{~min}$ before the start of the electroadsorption experiment to ensure that the electrode reached a stable state. The chromium(VI) concentration was determined at $540 \mathrm{~nm}$ with a $722 \mathrm{~s}$ spectrophotometer. The electrosorption capacity and removal efficiency were evaluated using the following equations

$$
\begin{aligned}
& R=\left(C_{0}-C_{\mathrm{e}}\right) / C_{0} \times 100 \% \\
& q_{\mathrm{e}}=\left(C_{0}-C_{\mathrm{e}}\right) \mathrm{V} / \mathrm{m}
\end{aligned}
$$

where $C_{0}$ is the initial concentration of chromium(VI) ions $\left(\mathrm{mg} \mathrm{L}^{-1}\right), C_{\mathrm{e}}$ is the final concentration of chromium(VI) ions $\left(\mathrm{mg} \mathrm{L}^{-1}\right), V(\mathrm{~L})$ is the total volume of the chromium(VI) aqueous solution, and $m$ is the mass of active CPC loaded on nickel foam $(\mathrm{g})$.

\section{ASSOCIATED CONTENT}

\section{Supporting Information}

The Supporting Information is available free of charge at https://pubs.acs.org/doi/10.1021/acsomega.1c03337.

SEM images of CHC (a) and DCHC (b) (Figure S1); SEM image of CPC (Figure S2); SEM images of CPC400 (a) and CPC-550 (b) (Figure S3); $\mathrm{N}_{2}$ adsorptiondesorption isotherm (a) and pore size distribution (b) of $\mathrm{CHC}$ (Figure S4); and removal efficiency of different adsorbents for chromium(VI) (Table S1) (PDF)

\section{AUTHOR INFORMATION}

\section{Corresponding Author}

Xiaonan Wu - Department of Chemical Engineering, Hebei Petroleum University of Technology, Chengde 067000, P. R. China; (1) orcid.org/0000-0002-4744-3656;

Email:chg178@126.com 


\section{Authors}

Xiaofei Zhang - Department of Chemical Engineering, Hebei Petroleum University of Technology, Chengde 067000, P. R. China

Bo Ren - Institute for Interdisciplinary Biomass Functional Materials Studies, Jilin Engineering Normal University, Changchun 130052, P. R. China

Xin Yan - Department of Chemical Engineering, Hebei Petroleum University of Technology, Chengde 067000, P. R. China

Yu Sun - Department of Chemical Engineering, Hebei Petroleum University of Technology, Chengde 067000, P. R. China

Hongcheng Gao - Department of Chemical Engineering, Hebei Petroleum University of Technology, Chengde 067000, P. R. China

Feng Qu - Department of Chemical Engineering, Hebei Petroleum University of Technology, Chengde 067000, P. R. China

Complete contact information is available at:

https://pubs.acs.org/10.1021/acsomega.1c03337

\section{Author Contributions}

X.Z. and B.R. contributed equally to this work. The manuscript was written through contributions of all authors. All authors have given approval to the final version of the manuscript.

Notes

The authors declare no competing financial interest.

\section{ACKNOWLEDGMENTS}

This work was supported by the Natural Science Foundation of Hebei Province, China (No. B2017411009).

\section{REFERENCES}

(1) Yasir, M. W.; Capozzi, S. L.; Kjellerup, B. V.; Mahmood, S.; Mahmood, T.; Khalid, A. Simultaneous biotreatment of hexavalent chromium $\mathrm{Cr}(\mathrm{VI})$ and polychlorinated biphenyls (PCBs) by indigenous bacteria of Co-polluted wastewater. Int. Biodeterior. Biodegrad. 2021, 161, No. 105249.

(2) Zhou, L.; Zhang, G. L.; Tian, J.; Wang, D. F.; Cai, D. Q.; Wu, Z. Y. Functionalized $\mathrm{Fe}_{3} \mathrm{O}_{4} @ \mathrm{C}$ nanospheres with adjustable structure for efficient hexavalent chromium removal. ACS Sustainable Chem. Eng. 2017, 5, 11042-11050.

(3) Yang, Q.; Wang, H. L.; Li, F. B.; Dang, Z.; Zhang, L. J. Rapid and efficient removal of $\mathrm{Cr}(\mathrm{VI})$ by a core-shell magnetic mesoporous polydopamine nanocomposite: roles of the mesoporous structure and redox-active functional groups. J. Mater. Chem. A 2021, 9, 1330613319.

(4) Lou, J. L.; Yu, S. K.; Feng, L. F.; Guo, X. N.; Wang, M.; Branco, A. T.; Li, T.; Lemos, B. Environmentally induced ribosomal DNA (rDNA) instability in human cells and populations exposed to hexavalent chromium [Cr (VI)]. Environ. Int. 2021, 153, No. 106525.

(5) Fan, C. H.; Qian, J. S.; Yang, Y.; Sun, H. Q.; Song, J. P.; Fan, Y. $\mathrm{R}$. Green ceramsite production via calcination of chromium contaminated soil and the toxic $\mathrm{Cr}(\mathrm{VI})$ immobilization mechanisms. J. Cleaner Prod. 2021, 315, No. 128204.

(6) Fu, F. L.; Wang, Q. Removal of heavy metal ions from wastewaters: A review. J. Environ. Manage. 2011, 92, 407-418.

(7) Duru, I.; Ege, D.; Kamali, A. R. Graphene oxides for removal of heavy and precious metals from wastewater. J. Mater. Sci. 2016, 51, 6097-6116.

(8) Hua, M.; Zhang, S. J.; Pan, B. C.; Zhang, W. M.; Lv, L.; Zhang, Q. X. Heavy metal removal from water/wastewater by nanosized metal oxides: a review. J. Hazard. Mater. 2012, 211-212, 317-331.
(9) Wang, H. M.; Song, X. Y.; Zhang, H. H.; Tan, P.; Kong, F. X. Removal of hexavalent chromium in dual-chamber microbial fuel cells separated by different ion exchange membranes. J. Hazard. Mater. 2020, 384, No. 121459.

(10) Yang, M. G.; Wang, X. W.; Meng, Y. Q.; Wang, M. Y. Recovery of chromium from vanadium precipitated solution by precipitation with lead salt and leaching with sodium carbonate. Hydrometallurgy 2020, 198, No. 105501.

(11) Kyaw, H. H.; Myint, M. T. Z.; Al-Harthi, S.; Al-Abri, M. Removal of heavy metal ions by capacitive deionization: Effect of surface modifification on ions adsorption. J. Hazard. Mater. 2020, 385, No. 121565.

(12) Li, Y.; Qi, J. W.; Li, J. S.; Shen, J. M.; Liu, Y. X.; Sun, X. Y.; Shen, J. Y.; Han, W. Q.; Wang, L. J. Nitrogen-Doped Hollow Mesoporous Carbon Spheres for Efficient Water Desalination by Capacitive Deionization. ACS Sustainable Chem. Eng. 2017, 5, 66356644.

(13) Leong, Z. Y.; Yang, H. Y. Capacitive Deionization of Divalent Cations for Water Softening Using Functionalized Carbon Electrodes. ACS Omega 2020, 5, 2097-2106.

(14) Liu, L. J.; Guo, X. R.; Tallon, R.; Huang, X. K.; Chen, J. H. Highly porous $\mathrm{N}$-doped graphene nanosheets for rapid removal of heavy metals from water by capacitive deionization. Chem. Commun. 2017, 53, 881-884.

(15) Liu, P.; Yan, T.; Shi, L.; Park, H. S.; Chen, X.; Zhao, Z.; Zhang, D. Graphene-based materials for capacitive deionization. J. Mater. Chem. A 2017, 5, 13907-13943.

(16) Han, C. L.; Meng, Q. H.; Cao, B.; Tian, G. Y. Enhanced Hybrid Capacitive Deionization Performance by Sodium Titanium Phosphate/Reduced Porous Graphene Oxide Composites. ACS Omega 2019, 4, 11455-11463.

(17) Li, H. B.; Pan, L. K.; Zhang, Y. P.; Zou, L. D.; Sun, C. Q.; Zhan, Y. K.; Sun, Z. Kinetics and thermodynamics study for electrosorption of $\mathrm{NaCl}$ onto carbon nanotubes and carbon nanofibers electrodes. Chem. Phys. Lett. 2010, 485, 161-166.

(18) Liu, Y.; Gao, X.; Wang, Z. P.; Wang, K.; Dou, X. Y.; Zhu, H. G.; Yuan, X.; Pan, L. K. Controlled synthesis of bismuth oxychloridecarbon nanofiber hybrid materials as highly efficient electrodes for rocking-chair capacitive deionization. Chem. Eng. J. 2021, 403, No. 126326.

(19) Zou, L.; Morris, G.; Qi, D. Using Activated Carbon Electrode in Electrosorptive Deionisation of Brackish Water. Desalination 2008, $225,329-340$.

(20) Wang, H.; Shi, L.; Yan, T.; Zhang, J.; Zhong, Q.; Zhang, D. Design of graphene-coated hollow mesoporous carbon spheres as high performance electrodes for capacitive deionization. J. Mater. Chem. A 2014, 2, 4739-4750.

(21) Li, Z.; Song, B.; Wu, Z. K.; Lin, Z. Y.; Yao, Y. G.; Moon, K. S.; Wong, C. P. 3D porous graphene with ultrahigh surface area for microscale capacitive deionization. Nano Energy 2015, 11, 711-718.

(22) Xu, P.; Drewes, J. E.; Heil, D.; Wang, G. Treatment of brackish produced water using carbon aerogel-based capacitive deionization technology. Water Res. 2008, 42, 2605-2617.

(23) Wang, G.; Pan, C.; Wang, L.; Dong, Q.; Yu, C.; Zhao, Z.; Qiu, J. Activated carbon nanofiber webs made by electrospinning for capacitive deionization. Electrochim. Acta 2012, 69, 65-70.

(24) El-Deen, A. G.; Barakat, N. A.; Khalil, K. A.; Kim, H. Y. Hollow carbon nanofibers as an effective electrode for brackish water desalination using the capacitive deionization process. New J. Chem. 2014, 38, 198-205.

(25) Nie, C.; Pan, L.; Li, H.; Chen, T.; Lu, T.; Sun, Z. Electrophoretic deposition of carbon nanotubes film electrodes for capacitive deionization. J. Electroanal. Chem. 2012, 666, 85-88.

(26) Wang, L.; Wang, M.; Huang, Z. H.; Cui, T. X.; Gui, X. C.; Kang, F. Y.; Wang, K. L.; Wu, D. H. Capacitive deionization of $\mathrm{NaCl}$ solutions using carbon nanotube sponge electrodes. J. Mater. Chem. 2011, 21, 18295-18299. 
(27) Chen, B.; Ma, Q. L.; Tan, C. L.; Lim, T. T.; Huang, L.; Zhang, $\mathrm{H}$. Carbon-based sorbents with three-dimensional architectures for water remediation. Small 2015, 11, 3319-3336.

(28) Liu, G. W.; Qiu, L.; Deng, H.; Wang, J. B.; Yao, L.; Deng, L. B. Ultrahigh surface area carbon nanosheets derived from lotus leaf with super capacities for capacitive deionization and dye adsorption. Appl. Surf. Sci. 2020, 524, No. 146485.

(29) Li, B.; Geng, D.; Lee, X. S.; Ge, X.; Chai, J.; Wang, Z.; Zhang, J.; Liu, Z.; Hor, T. S. A.; Zong, Y. Eggplant-derived microporous carbon sheets: towards mass production of efficient bifunctional oxygen electrocatalysts at low cost for rechargeable $\mathrm{Zn}$-air batteries. Chem. Commun. 2015, 51, 8841-8844.

(30) Liu, S. H.; Tang, Y. H. Hierarchically porous biocarbons prepared by microwave-aided carbonization and activation for capacitive deionization. J. Electroanal. Chem. 2020, 878, No. 114587. (31) Zhao, S. S.; Yan, T. T.; Wang, Z.; Zhang, J. P.; Shi, L. Y.; Zhang, D. S. Removal of $\mathrm{NaCl}$ from saltwater solutions using micro/ mesoporous carbon sheets derived from watermelon peel via deionization capacitors. RSC Adv. 2017, 7, 4297-4305.

(32) Kim, J.; Choi, M. S.; Shin, K. H.; Kota, M.; Kang, Y.; Lee, S.; Lee, J. Y.; Park, H. S. Rational Design of Carbon Nanomaterials for Electrochemical Sodium Storage and Capture. Adv. Mater. 2019, 31, No. 1803444

(33) Fan, Y.; Yang, X.; Zhu, B.; Liu, P. F.; Lu, H. T. Micromesoporous carbon spheres derived from carrageenan as electrode material for supercapacitors. J. Power Sources 2014, 268, 584-590.

(34) Choi, B. G.; Chang, S. J.; Lee, Y. B.; Bae, J. S.; Kim, H. J.; Huh, Y. S. 3D heterostructured architectures of $\mathrm{Co}_{3} \mathrm{O}_{4}$ nanoparticles deposited on porous graphene surfaces for high performance of lithium ion batteries. Nanoscale 2012, 4, 5924-5930.

(35) Wang, Z. L.; Xu, D.; Wang, H. G.; Wu, Z.; Zhang, X. B. In situ fabrication of porous graphene electrodes for high-performance energy storage. ACS Nano 2013, 7, 2422-2430.

(36) Wang, H.; Zhang, D. S.; Yan, T. T.; Wen, X. R.; Zhang, J. P.; Shi, L. Y.; Zhong, Q. D. Three-dimensional macroporous graphene architectures as high performance electrodes for capacitive deionization. J. Mater. Chem. A 2013, 1, 11778-11789.

(37) Li, J.; Liu, W.; Xiao, D.; Wang, X. Oxygen-rich hierarchical porous carbon made from pomelo peel fiber as electrode material for supercapacitor. Appl. Surf. Sci. 2017, 416, 918-924.

(38) Gong, Y.; Li, D.; Luo, C.; Fu, Q.; Pan, C. Highly porous graphitic biomass carbon as advanced electrode materials for supercapacitors. Green Chem. 2017, 19, 4132-4140.

(39) Shan, D. D.; Yang, J.; Liu, W.; Yan, J.; Fan, Z. J. Biomassderived three-dimensional honeycomb-like hierarchical structured carbon for ultrahigh energy density asymmetric supercapacitors. J. Mater. Chem. A 2016, 4, 13589-13602.

(40) Zhou, L.; Cao, H.; Zhu, S. Q.; Hou, L. R.; Yuan, C. Z. Hierarchical micro-/mesoporous $\mathrm{N}$-and $\mathrm{O}$-enriched carbon derived from disposable cashmere: a competitive cost effective material for high-performance electrochemical capacitors. Green Chem. 2015, 17, $2373-2382$.

(41) Wen, X. R.; Zhang, D. S.; Shi, L. Y.; Yan, T. T.; Wang, H.; Zhang, J. P. Three-dimensional hierarchical porous carbon with a bimodal pore arrangement for capacitive deionization. J. Mater. Chem. 2012, 22, 23835-23844.

(42) Xu, Y. X.; Lin, Z. Y.; Zhong, X.; Huang, X. Q.; Weiss, N. O.; Huang, Y.; Duan, X. F. Holey graphene frameworks for highly efficient capacitive energy storage. Nat. Commun. 2014, 5, No. 4554.

(43) Han, X. G.; Funk, M. R.; Shen, F.; Chen, Y. C.; Li, Y. Y.; Campbell, C. J.; Dai, J. Q.; Connell, J. W.; Barone, V.; Chen, Z. F.; Yang, X. F.; Kim, J. W.; Liao, Y. L.; Lin, Y.; Hu, L. B. Scalable Holey Graphene Synthesis and Dense Electrode Fabrication Toward High Performance Ultracapacitors. ACS Nano 2014, 8, 8255-8265.

(44) Ai, J. Y.; Li, J. B.; Li, K.; Yu, F.; Ma, J. Highly flexible, selfhealable and conductive poly(vinyl alcohol) $/ \mathrm{Ti}_{3} \mathrm{C}_{2} \mathrm{Tx}$ MXene film and it's application in capacitive deionization. Chem. Eng. J. 2021, 408, No. 127256
(45) Zhao, Y.; Hu, X. M.; Jiang, B. H.; Li, L. Optimization of the operational parameters for desalination with response surface methodology during a capacitive deionization process. Desalination 2014, 336, 64-71.

(46) Zhong, M.; Song, Y.; Li, Y.; Ma, C.; Zhai, X.; Shi, J.; Guo, Q.; Liu, L. Effect of Reduced Graphene Oxide on the Properties of an Activated Carbon Cloth/Polyaniline Flexible Electrode for Supercapacitor Application. J. Power Sources 2012, 217, 6-12.

(47) AlMarzooqi, F. A.; Al Ghaferia, A. A.; Saadata, I.; Hilalb, N. Application of capacitive deionisation in water desalination: a review. Desalination 2014, 342, 3-15.

(48) Kim, T.; Yoon, J. CDI ragone plot as a functional tool to evaluate desalination performance in capacitive deionization. RSC Adv. 2015, 5, 1456-1461.

(49) Wimalasiri, Y.; Mossad, M.; Zou, L. Thermodynamics and kinetics of adsorption of ammonium ions by graphene laminate electrodes in capacitive deionization. Desalination 2015, 357, 178188

(50) Zhang, Z.; Lan, H.; Liu, H.; Qu, J. Removal of tetracycline antibiotics from aqueous solution by amino-Fe(III) functionalized SBA15. Colloids Surf., A 2015, 471, 133-138.

(51) Namasivayam, C.; Kadirvelu, K. Uptake of mercury (II) from wastewater by activated carbon from an unwanted agricultural solid by-product: coirpith. Carbon 1999, 37, 79-84.

(52) Benguella, B.; Benaissa, H. Cadmium removal from aqueous solutions by chitin: kinetic and equilibrium studies. Water Res. 2002, 36, 2463-2474.

(53) Yan, R. Q.; Qiu, Z. F.; Bian, X. T.; Yang, J.; Lyu, S.; Zhou, A. H. Effective adsorption of antimony from aqueous solution by cerium hydroxide loaded on Y-tape molecular sieve adsorbent: Performance and mechanism. Colloids Surf., A 2020, 604, No. 125317.

(54) Macías-García, A.; Gómez, C. M.; Alfaro, D. M.; Alexandre, F. M.; Martínez, N. J. Study of the adsorption and electroadsorption process of $\mathrm{Cu}$ (II) ions within thermally and chemically modified activated carbon. J. Hazard. Mater. 2017, 328, 46-55.

(55) Gaikwad, M. S.; Balomajumder, C. Simultaneous electrosorptive removal of chromium(VI) and fluoride ions by capacitive deionization (CDI): Multicomponent isotherm modeling and kinetic study. Sep. Purif. Technol. 2017, 186, 272-281.

(56) Gaikwad, M. S.; Balomajumder, C.; Tiwari, A. K. Acid treated RHWBAC electrode performance for $\mathrm{Cr}(\mathrm{VI})$ removal by capacitive deionization and CFD analysis study. Chemosphere 2020, 254, No. 126781.

(57) Liu, Y. X.; Yuan, D. X.; Yan, J. M.; Li, Q. L.; Ouyang, T. Electrochemical removal of chromium from aqueous solutions using electrodes of stainless steel nets coated with single wall carbon nanotubes. J. Hazard. Mater. 2011, 186, 473-480. 